\title{
Polyazaacenes: new tricks for old dogs*
}

\author{
Fred Wudlt, Panayiotis A. Koutentis, Amir Weitz, Bin Ma, \\ Thomas Strassner, Kendall N. Houk and Saeed I. Khan \\ Exotic Materials Institute, Department of Chemistry and Biochemistry, \\ University of California, Los Angeles, California 90095-1569, USA
}

\begin{abstract}
The evolution of heterocycles from hexaazaanthracene to tetraazapentacenes led to the discovery that syn aza-substituted polyazaacenes possess unusual zwitterionic structures. One of these, 5,7-diphenyl-5H,12H-quinoxalino[2,3-b]phenazine 4, first claimed in 1898 was fully characterized, including an X-ray crystal structure. These heteroacenes have a low calculated singlet-triplet gap and have unusual photophysical properties.
\end{abstract}

\section{INTRODUCTION}

We recently reported that tetraphenylhexaazaanthracene TPHA $\mathbf{1}$ had a zwitterionic structure with a small calculated singlet/triplet gap, $\Delta \mathrm{E}_{\mathrm{S}-\mathrm{T}}=-18.9 \mathrm{kcal} / \mathrm{mol}$ [1]. The preference for structure $\mathbf{1}$ over structure $\mathbf{2}$ arises from formation of a 'double barreled' cyanine dye with two independent cationic and anionic cyanine subunits. The central benzene ring [2] of $\mathbf{2}$ was sacrificed in order to overcome the molecules' potential $16 \pi$ antiaromaticity [1] (Scheme 1).<smiles></smiles>

TPHA, 1<smiles>Cn1c(-c2ccccc2)nn(-c2ccccc2)c2cc3[nH]c(-c4ccccc4)nn(-c4ccccc4)c3cc21</smiles>

2

\section{Scheme 1}

Since the preparation of $\mathbf{1}$ was tedious and the mechanism of the last step was unknown [1], we wanted to determine if calculations [3] on larger and easier to prepare polyazaacenes gave a reduction of the calculated singlet/triplet energy gap $\left(\Delta \mathrm{E}_{\mathrm{S}-\mathrm{T}}\right)$, while maintaining the zwitterionic ground state. Indeed, $\mathrm{A}$ significant reduction occurs when the nitrogens in the 2 and 8 positions of the TPHA model were replaced with carbon atoms from fusion of aromatic rings on the flanks of the tetraazaanthracene. Since the phenyl substituents of TPHA have little effect on the singlet/triplet energy gap (Hammett $\sigma, H=0.00$, $\mathrm{Ph}=-0.01$ ) [4], for the purpose of preliminary modeling calculations the phenyl groups have been replaced by protons. These calculations on the model for tetraazapentacenediyl $\mathbf{3}$ indicated a singlet zwitterionic ground state and $\Delta \mathrm{E}_{\mathrm{S}-\mathrm{T}}=-11.4 \mathrm{kcal} / \mathrm{mol}$ (Scheme 2).<smiles>Cc1nnc(-c2ccccc2)c2cc3c(cc12)N(c1ccccc1)C(c1ccccc1)=NN3c1ccccc1</smiles>

2<smiles>Cn1c2ccccc2[nH]c2cc3[nH]c4ccccc4[nH]c3cc21</smiles>

3

Scheme 2

*Lecture presented at the 9th International Symposium on Novel Aromatic Compounds (ISNA-9), Hong Kong, China, 2-7 August 1998, pp. 0000-0000.

$\dagger$ Corresponding author: E-mail: wudl@chem.ucla.edu 
A previous, lower level calculation on $5 H, 7 H$-Quinoxalino[2,3- $b$ ]phenazinediyl 3 gave as result a stable singlet $\left(\Delta \mathrm{E}_{\mathrm{S}-\mathrm{T}}=-0.30 \mathrm{eV},-6.9 \mathrm{kcal} / \mathrm{mol}\right)$ [5]. Further, it was claimed that a large energy gap between the two partially occupied molecular orbitals suggested a valence-bond interaction of the unpaired electrons and a build up of a singlet ground state. This was attributed to the ability of the $\mathrm{NH}$ groups to participate in the $\pi$-sconjugation by their partially delocalized lone pairs. However, no structure was proposed and in light of the structure of TPHA and our modeling studies we postulate that the singlet ground state of $5 H, 7 H$-quinoxalino[2,3-b]phenazinediyl $\mathbf{4}$ should be a zwitterion. We therefore set out to synthesize and characterize $5 H, 7 H$-quinoxalino[2,3-b]-phenazines to compare their properties with those of TPHA (Scheme 3).

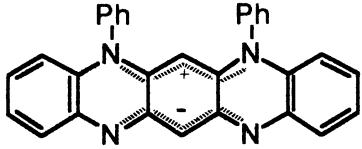

5,7-DPQP, 4

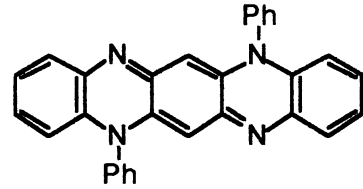

5,12-DPQP, 5

Scheme 3

$5 H, 7 H$-Dihydroquinoxalino[2,3- $b]$ phenazinediyl 3 is not known. The only dihydro-quinoxalino[2,3$b$ ]phenazine is the $5 H, 14 H$-dihydro derivative thought to be in equilibrium with the $5 H, 12 H$-dihydro isomer [6]. However, 5,7-diphenyl-5H,12H-quinoxalino[2,3-b]-phenazine (diphenylisofluorindine, 5,7$\mathrm{DPQP}, 4)$ exists [7] and is analogous to tetraaza-pentacenediyl 3. The preparation of 5,7-DPQP from the treatment of 3-imino- $N, 5$-diphenyl-3H,5 $\mathrm{H}$-2-phenazinamine (3-anilinoaposafranine) with $\mathrm{N}$-phenyl-1,2benzenediamine 6 was reported 100 years ago and except for one patent publication in 1901 has since not been mentioned [7]. The product was identified by microanalysis and by comparison of its physical appearance and color in solution with its more commonly known isomer 5,12-diphenyl-5H,12 $\mathrm{H}$ quinoxalino[2,3-b]phenazine (diphenylfluorindine, 5,12-DPQP, 5) [8]. Both isomers dissolve in acid to give a blue solution with a red fluorescence but only the free base of 5,12-DPQP was observed to fluoresce strongly to the naked eye whilst that of the 5,7-DPQP did not. Both compounds crystallize to give blue-green crystals with a metallic luster. Various preparations of 5,12-DPQP are reported [8]. In particular the treatment of 3-anilinoaposafranine with $\mathrm{N}$-phenyl-1,2-benzenediamine $\mathbf{6}$ and one equivalent of mineral acid to give 5,12-DPQP [8] affords a mixture of two isomeric products that require careful separation [9]. We therefore decided to 'modernize' the synthesis to produce the desired isomer regiospecifically.

\section{SYNTHESIS}

We successfully carried out a rational synthesis that affords 5,7-DPQP unambiguously and in good yield. (Scheme 4).

1,5-Difluoro-2,4-dinitrobenzene 7 reacts with $N$-substituted-1,2-benzenediamines 6 to give dinitrobenzenediamines $\mathbf{8}$ in good yields [10]. Hydrogenation of compounds $\mathbf{8}$ gave the benzenetetraamines $\mathbf{9}$, which on simple heating in ethanol in the presence of air gave the free base 4 . The benzenetetraamine 9 was very susceptible to oxidation and its isolation and characterization was only carried out for characterization purposes only. Treatment of 9 with ethanol and hydrochloric acid gave the hydrochloride salt of 5,7-DPQP which could be liberated with aqueous hydroxide.

Nearly quantitative yields were obtained for the preparation of compound $\mathbf{8}$ with the use of four equivalents of benzenediamine $\mathbf{6}$. The cost, however, of preparing more complex diamines $\mathbf{6}$ prevented the repeated use of fourfold excesses and despite lower yields the use of two equivalents of diamine $\mathbf{6}$, followed by two equivalents of Hünig's base was preferred. The overall synthesis, analogous to that used for the preparation of $5 H, 14 \mathrm{H}$-quinoxalino[2,3-b]phenazine from 1,5-dichloro-2,4-dinitrobenzene and excess 1,2-benzene-diamine [11], allows the preparation of a variety of 5,7-disubstituted quinoxalinophenazines, to be described in a separate publication. 
<smiles>Nc1ccccc1Nc1ccccc1</smiles>

6<smiles>O=[N+]([O-])c1cc([N+](=O)[O-])c(F)cc1F</smiles>

7

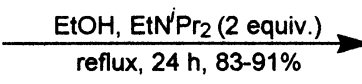

reflux, 24 h, 83-91\%<smiles>O=[N+]([O-])c1cc(Nc2ccccc2Nc2ccccc2)c([N+](=O)[O-])cc1Nc1ccccc1</smiles>

8<smiles>Nc1cc(N)c(Nc2ccccc2Nc2ccccc2)cc1Nc1ccccc1Nc1ccccc1</smiles>

9, $\mathrm{R}=\mathrm{Ph}$

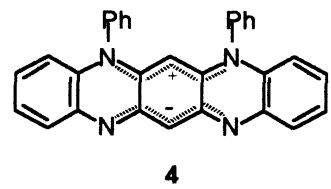

4

4
2) $\mathrm{NaOH}(\mathrm{aq}), 91 \%$

or EtOH, air, reflux, $84 \%$

Scheme 4 Synthetic route to symmetrical 5,7-disubstituted quinoxalinophenazines 4 .

\section{Mechanistic rationale}

The mechanism for the cyclization closely follows that proposed for the synthesis of dihydroquinoxalino[2,3-b]phenazine [11]. A dilute solution of tetraamine 9 in $\mathrm{CH}_{2} \mathrm{Cl}_{2}\left(\lambda_{\max } 241 \mathrm{~nm}\right)$, at $\approx 20^{\circ} \mathrm{C}$, becomes brown in color (over $24 \mathrm{~h}$ ) and absorption spectroscopy shows the formation of two new strong absorptions at 283 and $472 \mathrm{~nm}$; the absorption at $241 \mathrm{~nm}$ is no longer visible. Over a period of 7 days the intensity of the absorption at $472 \mathrm{~nm}$ decreases until the spectrum resembles that of 5,7-DPQP; the solution's color changing from brown to green. This suggests that the first cyclization to give presumably phenazine $\mathbf{1 2}$ is more rapid than the second cyclization to give 5,7-DPQP 4. A probable mechanism is described in Scheme 5. Air oxidation of benzenetetraamine $\mathbf{9}$ gives species $\mathbf{1 0}$ which can cyclize via nucleophilic attack of the diphenylamine on the $\mathrm{NH}$ imine to give $\mathbf{1 1}$ and ultimately quinoxalinophenazine 4.

In principle, this synthesis is applicable to the preparation of larger oligomers and is being pursued.

\section{CHARACTERIZATION}

The 5,7-DPQPs obtained were characterized by ${ }^{1} \mathrm{H}$ and ${ }^{13} \mathrm{C}$ NMR, UV/VIS, MS and IR spectroscopies as well as mp, TGA, DSC, microanalysis and single crystal X-ray diffraction.

\section{X-ray diffraction studies (Fig. 1)}

The crystal structure of compound $\mathbf{4}$ shows the heterocyclic portion of the molecule to be essentially planar. A molecule of dichloromethane was incorporated and was disordered over two partial occupancy sites, somewhat hampering the structure refinement. The molecules pack in a staggered sheet type structure. Each sheet is two molecules deep and the heterocycles dimerize by aligning the heterocyclic portions face to face with the phenyl substituents facing in opposing directions, the overlap, however, is not perfect. A separation of $\approx 3.58 \AA$ between the heterocyclic faces suggests a weak $\pi-\pi$ intermolecular interaction. The next sheet is $\approx 4.84 \AA$ away and staggered one benzene ring to the side. Within one dimer a further intermolecular interaction could be possible. The ortho protons of the phenyl substituents could interact with the nitrogens of the negative portion of the zwitterion but these distances are only equivalent to the sum of the Van der Waal's radii for nitrogen and hydrogen $(1.5$ and $1.2 \AA$, respectively) [12]. 


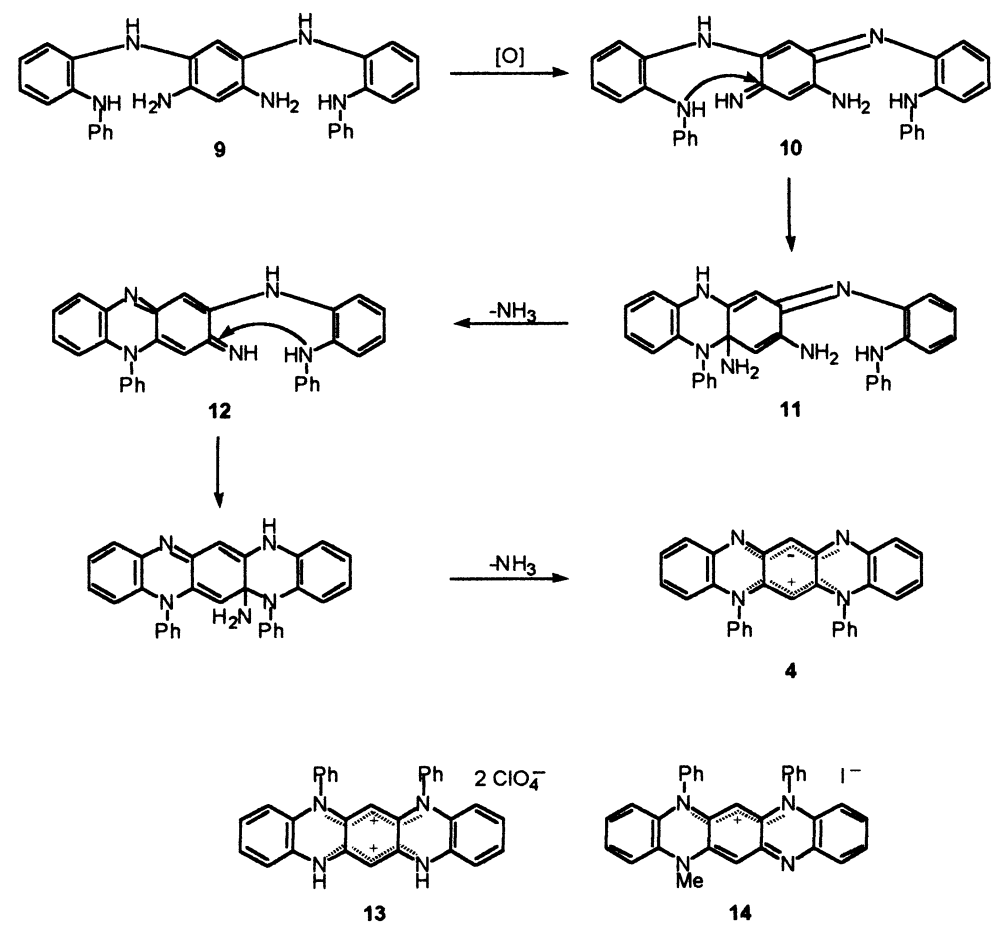

Scheme 5 Proposed mechanistic rationale for the formation of quinoxalinophenazine 4 from $\mathbf{9}$.

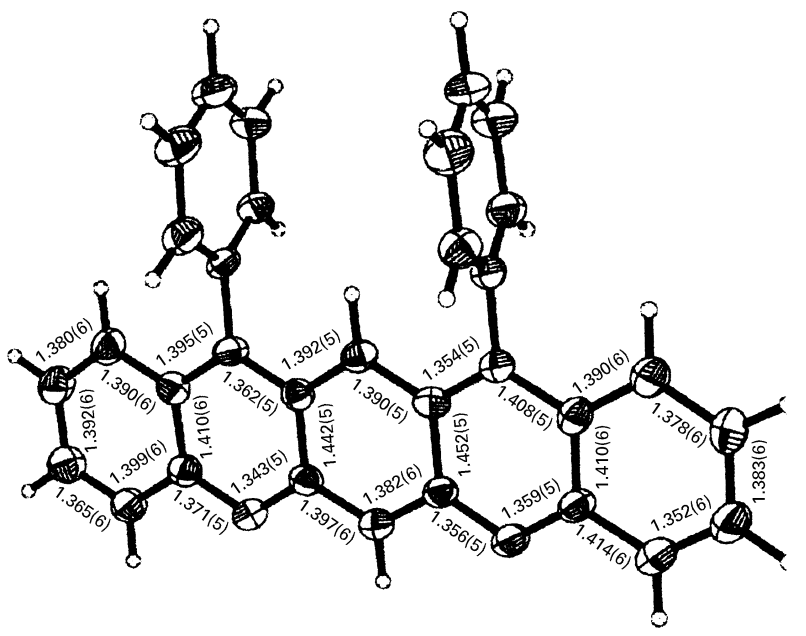

Fig. 1 Ortep view of compound $\mathbf{4}$ with selected bond lengths $(\AA)$.

\section{NMR and modeling studies}

The diphenyl derivative 4 was fully optimized using DFT (Becke3LYP/6-31G*, basis). The calculations suggested the singlet was more stable than the triplet by $10.1 \mathrm{kcal} / \mathrm{mol}$ in close agreement with the calculations on tetraazapentacenediyl 3, $\Delta \mathrm{E}_{\mathrm{S}-\mathrm{T}}=-11.4 \mathrm{kcal} / \mathrm{mol}$. ${ }^{1} \mathrm{H}$ NMR study of $5,7-\mathrm{DPQP}$ revealed two singlets at 6.16 and 4.25 p.p.m. which belong to the central ring protons $\mathrm{H} 13$ and H6, respectively (from NOE NMR) [13]. The high field signal at 4.25 p.p.m. indicates that the proton at H6 is strongly shielded by the two phenyl rings and suggests that the phenyl substituents at N5 and N7 are essentially perpendicular to the plane of the quinoxalino[2,3-b]phenazine ring (see Fig. 1). For comparison the equivalent proton, H10, of TPHA is a singlet at 5.15 p.p.m. and the 'peri' phenyl rings at N1 and N9 are shown, by X-ray crystallography, to be twisted out of the plane of the hexaazaanthracene ring by $\approx 62$ 
and $65^{\circ}$ [1]. Heterocycle 4 was not sufficiently soluble for a ${ }^{13} \mathrm{C}$ NMR study. The calculated highest occupied molecular orbital (HOMO) was not degenerate and shows a large lobe on carbon C13 but virtually nothing for carbon $\mathrm{C6}$, nevertheless the HOMO-1, which is very close in energy, shows a considerable lobe on carbon C6 (see Fig. 2).

Simulation of the electrostatic potential surface of the 5,7-diphenyl 4 strongly supports the chargeseparation and agrees with the proposed zwitterionic structure of 5,7-DPQP (Fig. 3). The calculated dipole moment for the singlet state of $5 H, 7 H$-quinoxalino[2,3-b]phenazine 4 was $9.8 \mathrm{D}$.
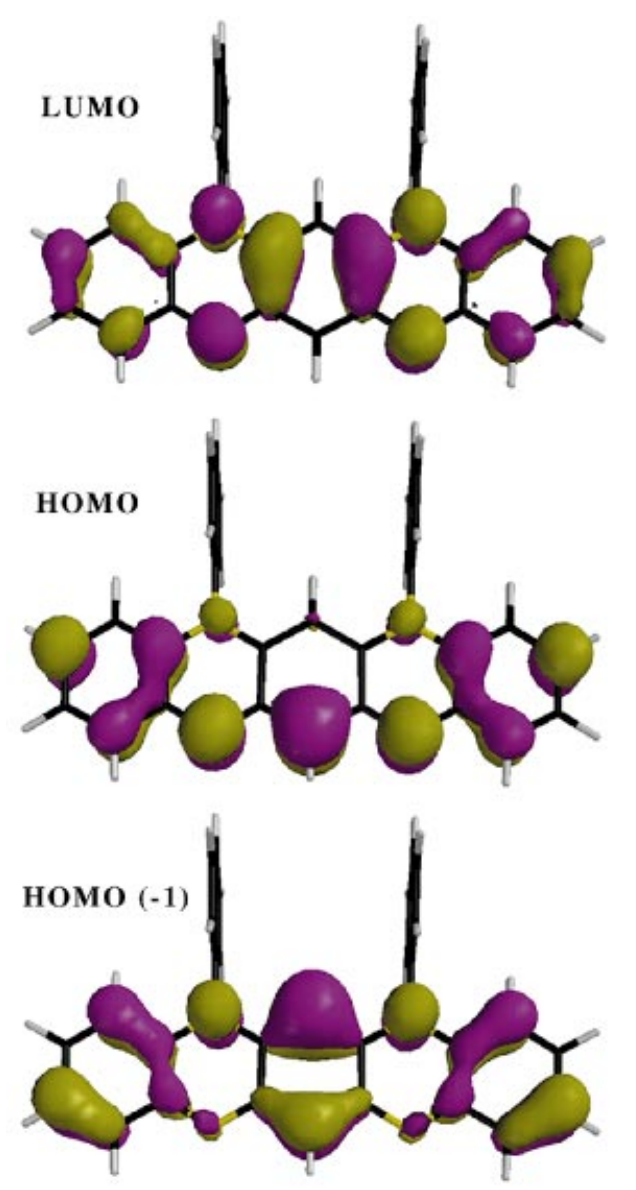

Fig. 2 LUMO, HOMO and one of the two degenerate HOMO-1 orbitals of 5,7-DPQP 4.

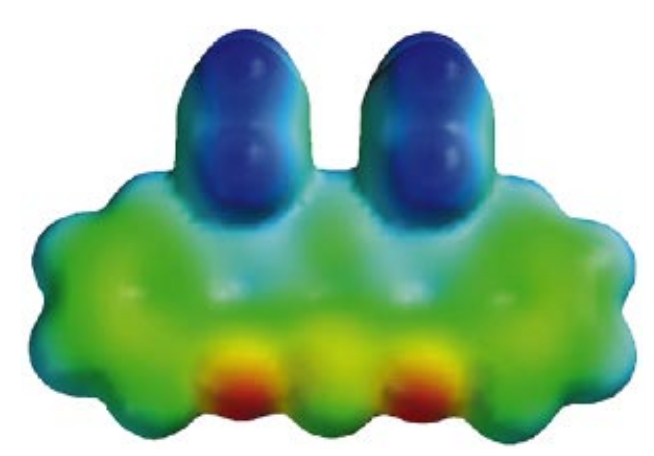

Fig. 3 Calculated electrostatic surface plot of 5,7-DPQP 4; red color represents a negative electrostatic potential and blue represents a positive electrostatic potential. The blue (positive) of the phenyl rings is an artifact. 


\section{UV/visible and fluorescence studies}

The observed symmetry of 5,7-DPQP in the ${ }^{1} \mathrm{H}$ NMR spectrum supports a zwitterion analogous to TPHA and this was further supported by the absorption properties. Heterocycle $\mathbf{4}$ dissolves in most polar organic solvents to give a green-colored solution and shows negative solvatochromism, typical of zwitterionic compounds (Fig. 4) [14].

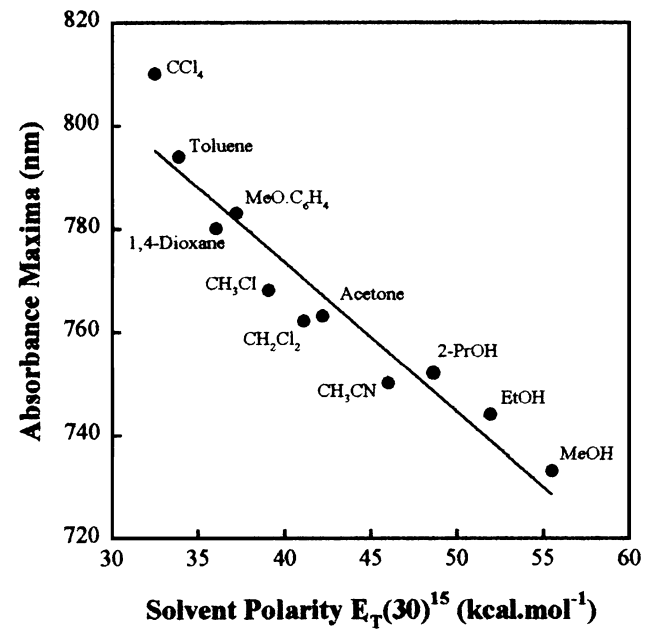

Fig. 4 Correlation between solvent polarity $E \mathrm{~T}(30)$ [15] and the maximium $\pi-\pi^{*}$ absorption of 5,7-DPQP 4 $(n=11 ; r=0.95 ;$ slope $=-2.95)$.

A significant blue shift $(\approx 100 \mathrm{~nm})$ of the low energy $\pi-\pi^{*}$ transitions, the color of the solution changing from green to blue, is observed on monoprotonation $\left[\mathrm{H}^{+} / \mathrm{EtOH}, \lambda_{\max } 660 \mathrm{~nm}(\log \varepsilon\right.$ 4.70)] or monomethylation [EtOH, $\lambda_{\max } 652 \mathrm{~nm}$ (4.56)]; bisprotonation gave a further blue shift $\left[\mathrm{H}^{+} / \mathrm{EtOH}, \lambda_{\max }\right.$ $639 \mathrm{~nm}$ (4.97)]. Mono and bisprotonation were achieved by the careful addition of (69-72\%) aqueous perchloric acid to a dilute ethanolic solution of the free base 4. Furthermore, on protonation or methylation, the transitions at $\approx 420 \mathrm{~nm}$ for the free base are lost. Presumably, these transitions are $n-\pi^{*}$ from the nitrogen atoms on the anionic portion of the cyanine dye (Fig. 5). In neutral ethanol the absorption spectrum of the bisperchlorate $\mathbf{1 3}$ could not be recorded since mono-deprotonation by the solvent gave the monoprotonated species [EtOH, $\lambda_{\max } 660 \mathrm{~nm}$ (4.68)] whose absorption spectrum was identical to that generated by the careful addition of dilute acid to an ethanolic solution of the free base above.

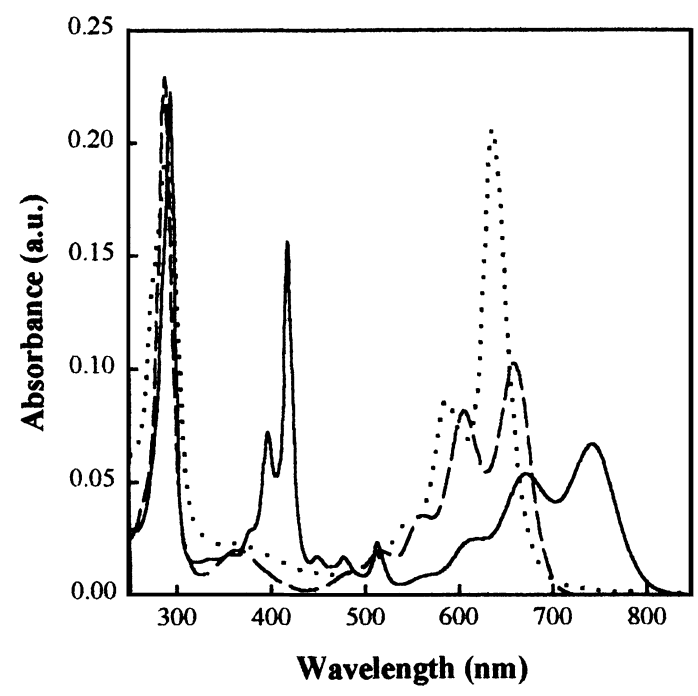

Fig. 5 Absorption spectra of 5,7-DPQP 4 in ethanol at $2.57 \times 10^{-6} \mathrm{M}$; [free base $\left(-\frac{1}{-} \lambda_{\max }=744 \mathrm{~nm}(\log \varepsilon\right.$ 4.55); monoprotonated (- -) $\lambda_{\max }=660 \mathrm{~nm}$ (4.70); bisprotonated $\left.(\ldots) \lambda_{\max }=639 \mathrm{~nm}(4.97)\right]$. 
For comparison TPHA shows a much smaller blue shift on increasing solvent polarity, a reflection of its smaller dipole moment (5.1 vs. $9.8 \mathrm{D}$ ); the low energy $\pi-\pi^{*}$ transitions are more structured and the $n-\pi^{*}$ transitions at $\approx 420 \mathrm{~nm}$ are very weak. On monomethylation or monoprotonation of TPHA the $\pi-\pi^{*}$ transitions experience a small red shift and the structure is lost. Bismethylation of TPHA causes a greater red shift causing the solution to become green and the weak $n-\pi^{*}$ transitions to intensify. It has been shown that methylation of either species mimics protonation.

TPHA has a strong fluorescence emission $\left(\Phi_{\mathrm{F}} 0.31\right.$, relative to rhodamine 640) that does not mirror the absorption spectrum [1]. 5,7-DPQP 4, however, shows a very weak emission $\left(\lambda_{\max } 792 \mathrm{~nm}, \Phi_{\mathrm{F}} 0.006\right)$, which increases on monoprotonation $\left(\lambda_{\max } 690 \mathrm{~nm}, \Phi_{\mathrm{F}} 0.10\right)$, or monomethylation and suffers a small blue shift. Bisprotonation results in a further blue shift and increase of fluorescence quantum yield $\left(\lambda_{\max }\right.$ $660 \mathrm{~nm}, \Phi_{\mathrm{F}} 0.16$ ) (Table 1, Fig. 6). 5,7-DPQP 4 therefore, behaves contrary to TPHA which shows smaller fluorescence quantum yields on protonation or methylation.

Table 1 Absorption and emission properties of compound $\mathbf{4}$ and its protonated derivatives

\begin{tabular}{llll}
\hline Compound & $\begin{array}{l}\text { Absorption } \\
\lambda_{\max } \operatorname{mm}(\log \varepsilon)^{*}\end{array}$ & $\begin{array}{l}\text { Emission } \\
\lambda_{\max }(\mathrm{nm})\end{array}$ & $\begin{array}{c}\text { Quantum yield } \\
\Phi_{\mathrm{F}}^{\dagger}\end{array}$ \\
\hline Neutral, $\mathbf{4}$ & $745(4.55)$ & 792 & 0.006 \\
Mono-protonated, 4 & $660(4.70)$ & 690 & 0.10 \\
Bis-protonated, 4 & $639(4.97)$ & 660 & 0.16 \\
Mono-methylated, $\mathbf{1 5}$ & $652(4.56)$ & 682 & 0.12 \\
\hline
\end{tabular}

*UV-vis recorded in ethanol stored over potassium carbonate, concentrations approximately $10^{-6} \mathrm{M}$. $\dagger$ Relative to Rhodhamine $101\left(\Phi_{\mathrm{F}}=1.0\right.$ in $\left.\mathrm{EtOH}\right)$.

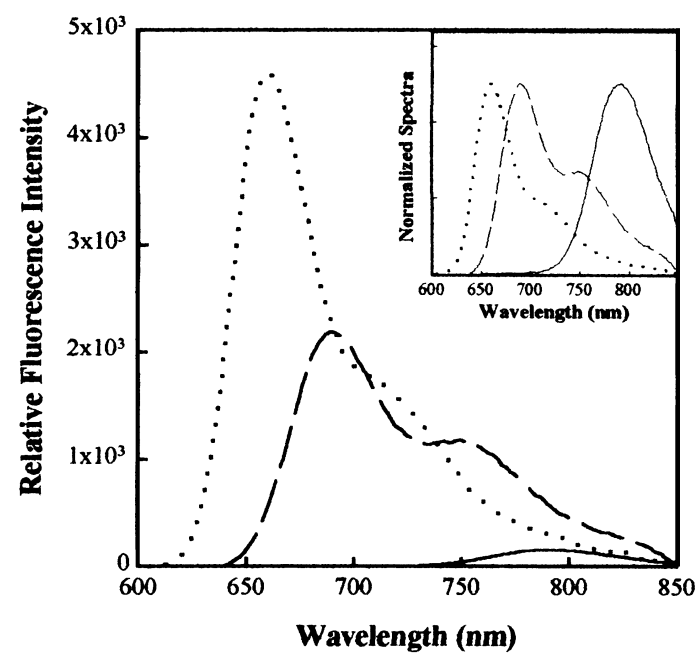

Fig. 6 Comparison of the fluorescence spectra of 5,7-DPQP 4 in ethanol (—_ ) with monoprotonated (- -) and bisprotonated $(\cdots)$ derivatives of $\mathbf{4}$ generated in acidified ethanol.

Whilst both TPHA and 5,7-disubstituted quinoxalinophenazine 4 are zwitterions, they show contrasting photophysical properties which remain unexplained.

A brief study of the isomeric 5,12-DPQP showed the neutral base to exhibit a very strong emission $\left(\Phi_{\mathrm{F}}\right.$ 0.71 ) which mirrors the absorption spectrum [16]. The first absorption peak maximum $(\approx 567 \mathrm{~nm})$ and the first fluorescence emission band $(\approx 572 \mathrm{~nm})$ correspond to a small Stokes shift of $5 \mathrm{~nm}$. In the presence of air and fluorescent light, the pink emission fades with time, leaving a colorless solution.

\section{CONCLUSION}

We have independently synthesized and characterized an early example of a double-barreled cyanine dye 
with a low predicted singlet/triplet energy gap. The compound 5,7-DPQP exists as a ground state zwitterionic singlet as shown by ${ }^{1} \mathrm{H}$ NMR and absorption spectroscopy. Furthermore, 5,7-DPQP shows little or no fluorescence as its free base.

\section{ACKNOWLEDGEMENT}

We thank the NSF for support through grant DMR 9812046.

\section{REFERENCES}

1 K. Hutchison, G. Srdanov, R. Hicks, H. Yu, F. Wudl. J. Am. Chem. Soc. 120, 2989-2990 (1998).

2 A similar sacrificing of the benzene ring was reported during a conformational study on symmetric 1,3,5trialkylamino-2,4,6-trinitro-benzenes. The molecules can exist either in a quinoid boat form or as a twist boat, the latter resulting from a formal coupling of a cationic with an anionic cyanine. No evidence, however, to support the presence of a charge seperated ground state was given. J. J. Wolff, H. Irngartinger, F. Gredel, I. Bolocan. Chem. Ber. 126, 2127-2131 (1993).

3 Molecular calculations were performed using density functional theory (DFT) [21] employing the GAUSSIAN-94 set of codes [22] implementing the unrestricted Hartree-Fock hybrid model Becke3LYP [23] the split valence double-zeta (DZ) basis set, 6-31G* [24].

4 D. H. McDaniel, H. C. Brown. J. Org. Chem. 23, 420-427 (1958).

5 J. Zhang, S. Karabunarliev, M. Baumgarten. Chem. Physics. 206, 339-351 (1996).

6 J. Armand, L. Boulares, C. Bellec, J. Pinson. Can. J. Chem. 65, 1619-1623 (1987).

7 F. Kehrmann, H. Bürgin. Chem. Ber. 29, 1820-1822 (1896); F. Kehrmann, A. Duret. Chem. Ber. 31, 2442-2444 (1898); D. R. P. Cassella \& Co. 142, 565; C II. 85 (1903); Frdl. 7, 345.

8 O. N. Witt. Chem. Ber. 20, 1538-1541(1887); O. Fischer, E. Hepp. Chem. Ber. 23, 2789-2793 (1890); O. Fischer, E. Hepp. Chem. Ber. 28, 293-301 (1895); F. Kehrmann, H. Bürgin. Chem. Ber. 29, 1246-1254 (1896).

9 V. C. Barry, J. G. Belton, J. F. O’Sullivan, D. Twomey. J. Chem. Soc. 888-893 (1956).

10 J. J. Kulagowski, C. W. Rees. Synthesis. 215 (1980).

11 R. Nietzki, J. Slaboszewicz. Chem. Ber. 34, 3727-3732 (1901).

12 R. C. Weast. CRC Handbook of Chemistry and Physics, 62nd edn, pp. D-166. CRC Press, Boca Raton (1981).

13 A. Bax, S. Subramanian. J. Magn. Reson. 67, 565-569 (1986).

14 C. Reichardt. Solvent Effects in Organic Chemistry, pp. 189-205. Verlag Chemie, Weinheim (1979).

15 C. Reichardt. Solvent Effects in Organic Chemistry, pp. 242-244. Verlag Chemie, Weinheim (1979).

16 The fluorescence quantum yields $\left(\Phi_{\mathrm{F}}\right)$ of 5,12-DPQP 5 in ethanol $\left(\Phi_{\mathrm{F}} 0.71\right)$ and dichloromethane $\left(\Phi_{\mathrm{F}} 0.74\right)$ were determined by using fluorescence standard Rhodamine $101\left(\Phi_{\mathrm{F}}=1.0\right.$ in ethanol), with a correction for the solvent refractive index.

17 P. J. S. Foot, V. Montgomery, P. Spearman. Mater. Sci. Forum, 191, 251-256 (1995); L. Sawtschenko, K. Jobst, A. Neudeck, L. Dunsch. Electrochim. Acta. 41, 123-131 (1996).

18 S. A. Jenekhe. Macromolecules 24, 1-10 (1991).

19 A. J. Fry. Synthetic Organic Electrochemistry, 2nd edn. John Wiley \& Sons, New York (1989).

20 I. C. Lewis, T. Edstrom. J. Org. Chem. 28, 2050-2057 (1963).

21 J. M. Seminario, P. Politzer. Modern Density Functional Theory. A Tool for Chemistry. Elsevier, Amsterdam (1995).

22 M. J. Frisch, et al. Gaussian 94, Revision B.2; Gaussian Inc., Pittsburgh, PA (1995).

23 A. D. Becke. J. Chem. Phys. 98, 1372-1377, 5648-5652 (1993).

24 B3LYP/6-31G* calculations predict a singlet-triplet gap of $39 \mathrm{kcal} / \mathrm{mol}$ for anthracene (experiment $=42 \mathrm{kcal} /$ mol). 